\title{
Study Day of Microbiology Specimen
}

National Cancer Institute

\section{Source}

National Cancer Institute. Study Day of Microbiology Specimen. NCI Thesaurus. Code C87903.

The day that a microbiology specimen is collected. 